\title{
Hayden White e o pluralismo histórico
}

\author{
Hayden White and Historical Pluralism
}

\section{Daniela KERN $\bullet$}

Resumo: Este artigo pretende explorar a relação de Hayden White com a crítica pluralista praticada pelos participantes da Escola de Chicago, e mais especificamente o conceito de pluralismo histórico proposto pelo autor em um de seus artigos não recolhido em livro, Historical Pluralism. A fim de conduzir a análise do conceito, será recuperado, em especial, o evento que motivou o texto de White, a saber, o debate público entre os críticos Wayne Booth, Abrams e Hillis Miller, ocorrido nos anos 70 .

Palavras-chave: Hayden White; Escola de Chicago; Pluralismo Histórico.

Abstract: This article explores the relationship between Hayden White and the critical pluralism practiced by the members of the Chicago School, and more specifically the concept of historical pluralism proposed by the author in one of his articles not published in book form, Historical Pluralism. In order to conduct the analysis of this proposed concept, the event that had motivated White's text will be discussed in particular, namely the public debate among the critics, Wayne Booth, Abrams and Hillis Miller, which occurred in the 70s.

Keywords: Hayden White; Chicago School; Historical Pluralism.

Se o pluralismo é uma visão válida, e é possível o respeito entre os sistemas de valores que não sejam necessariamente hostis um ao outro, então o que segue são tolerância e conseqüências liberais, o que não acontece no caso do monismo (somente um conjunto de valores é verdadeiro, todos os outros são falsos) ou do relativismo (os meus valores são meus, os seus valores são seus, e, se nós entrarmos em conflito, nenhum de nós pode reivindicar estar certo).

Isaiah Berlin, Meu percurso intelectual, 1997

Hayden White muitíssimas vezes é associado, sobretudo pelos historiadores que o criticam, aos pós-estruturalistas franceses ou ao movimento pós-moderno (com frequência tratados como equivalentes). O próprio White, no entanto, define a si mesmo como modernista. Evidentemente, muito já se falou sobre o caráter provisório, questionável e, às vezes, até mesmo inútil deste tipo de classificação. Ainda assim, considerando que o rótulo colocado em White repercute bastante na recepção de sua obra e faz com que seja mais lida entre pesquisadores de formação interdisciplinar do que entre os próprios historiadores, julgo relevante analisar uma das facetas do modernismo de White que pode ser rastreada em sua obra, o pluralismo histórico. Convém salientar que White mais de uma vez se vinculou publicamente ao pluralismo. Em março de 1984 participou, com a palestra Interpretation in criticism, da conferência interdisciplinar The foundations of critical pluralism,

\footnotetext{
- Professora Doutora - UFRGS - Univ. Federal do Rio Grande do Sul - Av. Paulo Gama, 110, CEP: 90040-060, Porto Alegre, Rio Grande do Sul, Brasil. E-mail: danielapmkern@yahoo.com.br
} 
organizada pela University of Nebraska e patrocinada pelo Critical Inquiry (renomado periódico pluralista da University of Chicago) em Lincoln, juntamente com pluralistas confessos como Wayne Booth (Pluralism in the classroom) e Richard McKeon (Pluralism of interpretation) e com o incansável crítico do pluralismo e herdeiro do New Criticism de Yale Stanley Fish (The impossibility of critical pluralism). Richard McKeon, filósofo, professor de Booth e um dos principais formuladores do pluralismo de Chicago, falece em 1985. Em homenagem a ele, a Critical Inquiry dedica ao pluralismo, em 1986, uma de suas edições. Desta edição Hayden White participa com o artigo Historical Pluralism, no qual se declara pluralista, ainda que não professe o mesmo pluralismo dos Chicagoans. Para tratar do pluralismo específico de White, tópico pouquíssimo mencionado na vasta bibliografia a ele dedicada, é necessário, antes de mais nada, contextualizar brevemente a tradição do pensamento pluralista americano e sintetizar as polêmicas entre pluralistas e desconstrutivistas que serão abordadas por White em seu artigo.

Comecemos por uma definição bastante simples: o pluralismo é uma reação ao chamado monismo filosófico. No século XX teremos quatro filósofos que se destacaram como anti-monistas: Wittgenstein, McKeon, Jacques Derrida e Richard Rorty. O anti-monismo de McKeon, batizado de pluralismo crítico, difere-se dos outros, conforme Richter, pelo aspecto construtivo: "Era o sonho fora de moda de McKeon de recuperar o pensamento do passado pela compreensão das ideias dos filósofos através da história como os produtos de suas escolhas semânticas individuais" (RICHTER, 2008). ${ }^{1}$ É a relação de Hayden White com essa tradição específica de anti-monismo que me interessa observar.

Antes de chegarmos diretamente a essa relação há, contudo, outro desvio necessário: uma vez que o pluralismo americano é pouco conhecido fora dos Estados Unidos, lembremos que McKeon não é o seu fundador. Tal título pode ser atribuído a William James (1842-1910), pertencente a uma geração anterior de modernistas. É provável que a perspectiva pluralista de James já se desenvolvesse nos tempos em que, médico recém-formado, acompanhou Louis Agassiz e Charles Frederick Hartt em uma expedição pelo Brasil, em 1865 - seus diários, com uma visão muito mais tolerante sobre negros, índios e sobre os brasileiros em geral, contrastam vivamente com os relatos de Agassiz. É apenas a partir de 1882, agora já psicólogo, que William James passará a teorizar sua visão pluralista, que conceituará como "um sistema de pensamento que reconhece mais de um princípio último" (RICHTER, 2008). Em 1909 publica a conferência A pluralistic universe, na qual, além de argumentar contra o monismo característico do racionalismo de pensadores como Kant e Hegel, então dominante no meio acadêmico, define as vantagens do pluralismo, reconhecendo sua dívida para com o empirismo inglês. William James, ao contrastar pluralismo e monismo, apresenta sua opinião sobre ambos: "Compromisso e mediação são inseparáveis da filosofia pluralista. Apenas o dogmatismo monista pode dizer de qualquer uma destas hipóteses: 'Ou é esta ou não é 
nenhuma; leve-a ou a deixe como está"” (JAMES, 1909). Para James, a realidade pode ser melhor apreendida sob uma ótica pluralista: "Para o pluralismo, tudo aquilo que precisamos admitir como a constituição da realidade é o que nós mesmos encontramos realizado em cada detalhe da vida finita. Em suma, nada real é absolutamente simples, mesmo a menor partícula de experiência é um multum in parvo pluralmente relacionado" (JAMES, 1909). Entre seus contemporâneos esse conjunto de ideias encontrou muitos opositores. O teor da refutação foi muito bem sintetizado por John Russell, filósofo que em 1907 travara um debate público com William James acerca do conceito de verdade: “(1) O Pluralismo apreende mal os fatos nos quais afirma se basear. (2) Dá uma interpretação essencialmente irracional a esses fatos. (3) O pluralismo torna o conhecimento impossível" (RUSSELL, 1909, p.373).

Ainda que os caminhos que conduzem o pluralismo de James a seus desdobramentos futuros sejam bastante tortuosos, há trilhas suficientemente visíveis: Arthur Lovejoy (1873-1962) foi seu aluno e, como o mestre, irá rejeitar enfaticamente o monismo, sobretudo em sua célebre obra The revolt against dualism (1930). Lovejoy era colega de Richard McKeon no Committee on the History of Ideas, pertencente ao ACLS (American Council of Learned Societies, criado em 1919) e ambos são co-fundadores do Journal of the History of Ideas. Além disso, Lovejoy trabalhou com Ronald Salmon Crane (1886-1967) em um projeto sobre a história do primitivismo. McKeon e Crane são os alicerces fundamentais do pluralismo crítico da Escola de Chicago, ${ }^{2}$ cujo texto fundador é History versus criticism in the study of literature (1935). A Escola de Chicago surge em meio à Grande Depressão Americana, e se oferece como uma reação e uma alternativa ao formalismo do New Criticism e ao seu método de close reading, reação que, no entanto, não abandona a análise intrínseca da obra, um dos cavalos de batalha dos modernistas. A solução para evitar o formalismo extremo dos new critics e, ao mesmo tempo, assegurar o rigor crítico nas análises de obras literárias é a retomada dos estudos de retórica e de poética aristotélicos. O método dos chicagoans pretende recuperar os diferentes modos de construção do texto sob uma perspectiva histórica tirada de Aristóteles, mas que permite a aproximação, nem sempre declarada, com uma visão marxista de história (Kenneth Burke, que também lecionou em Chicago e que é uma das principais influências de White em Meta-História, ao mesmo tempo em que passou a estudar retórica na Grande Depressão, aproximou-se do Partido Comunista). O monismo tanto de Hegel quanto do New Criticism é um dos principais alvos do grupo, assim como, segundo Sprinker, "o crescente prestígio da ciência positivista e de sua presumida consequência: a moderna sociedade industrial” (SPRINKER, 1995, p.193). Uma diferença crucial com relação ao marxismo, no entanto, ainda de acordo com Sprinker, é o papel atribuído ao sujeito: o autor e o leitor para os chicagoans são indivíduos livres, criativos "e relativamente não condicionados pela história e pelas condições materiais de uma dada formação social" (SPRINKER, 1995, p.202). Outra questão que se deve 
levar em conta são as mudanças no cenário acadêmico americano, com a crescente infiltração de paradigmas das ciências exatas e naturais na área das humanidades. Como bem avalia Sprinker,

As humanidades se tornam, sob este ponto de vista, o repositório de resistência à hegemonia intelectual das ciências naturais (especialmente da biologia e das ciências do comportamento) e sociologia. Elas protegem o sujeito humano de ser absorvido pelos discursos instrumentalistas destas disciplinas. As humanidades recebem o poder de competir contra as ciências pelo estabelecimento de métodos rigorosos de investigação e demonstração específica a seus próprios objetos de estudo - baseados na poética de Aristóteles - ao mesmo tempo em que seu real propósito era minar a autoridade das concepções instrumentais de homem que as ciências efetivamente estavam elaborando (SPRINKER, 1995, p.202).

O interesse pela retórica será redobrado na segunda geração dos críticos de Chicago, representada por Wayne Booth, discípulo direto de Crane. Booth acompanha de perto a mudança no cenário intelectual americano e o surgimento de um novo "inimigo": o desconstrucionismo e a consequente rejeição, nas palavras de Richter, de "qualquer teoria como produtora de conhecimento válido" (RICHTER, 2008). Neste cenário outro inimigo começa a surgir, o ecletismo, isto é, a combinação despreocupada de teorias cujos pressupostos são simplesmente incompatíveis. Quanto ao ambiente acadêmico na área de humanas, continua a passar por transformações que os modernistas eruditos da velha guarda julgam alarmantes. Assim é que o historiador da arte Ernest Gombrich, então presidente do prestigiado Instituto Warburg, publica em 1971 The state of art history: A plea for pluralism, artigo no qual defende a existência do pluralismo de métodos na área da história da arte, em contradição com o monismo metodológico que uma teoria como a dos paradigmas científicos de Thomas Kuhn pode acarretar. Grandes eruditos modernos, como Curtius e Auerbach, evidentemente não trabalhavam segundo a lógica do paradigma, e é de fato muito difícil tentar "aplicar" em outros contextos os "modelos" que desenvolveram em suas obras. Para Gombrich, e também para seu amigo Karl Popper, qualquer ciência é mantida em funcionamento pelo contínuo exercício do pensamento crítico. A aplicação de paradigmas prontos a quaisquer objetos de estudo científico antes refletiria as modas intelectuais do momento do que avançaria o conhecimento de fato. Com a consolidação da "indústria acadêmica", no entanto, o uso da lógica do paradigma ganha força. Gombrich tem uma explicação para isto:

[A indústria acadêmica] é uma indústria que demanda 'pesquisa', não devido a um forte desejo de verdade, mas bastante abertamente como uma qualificação por cargos e promoções. Quem pode culpar as vítimas de tal pressão se elas procuram o paradigma mais próximo e o aplicam a qualquer obra que lhes caia nas mãos? (GOMBRICH, 1971, p.86).

Note-se que os descostrucionistas passarão a fornecer grande quantidade de "paradigmas" 
para esta crescente indústria, diferentemente dos pluralistas de Chicago, cujos métodos não se adaptam tão bem a tal modelo.

É com semelhante cenário como pano de fundo que Wayne Booth, sem esquecer as lições do pai do pluralismo, William James, ${ }^{3}$ aproveita a polêmica estabelecida em 1972 entre o historiador da literatura Meyer Howard Abrams (1912) e o crítico desconstrucionista J. Hillis Miller, para defender o pluralismo (especialmente o de Chicago) e para questionar a nova corrente crítica francesa. Antes de passarmos ao texto de Booth, façamos mais uma digressão a fim de recuperar os “dados do processo". Hillis Miller reclamou em Tradition and difference, resenha do livro Natural Supernaturalism: tradition and revolution in romantic literature, que Abrams, o autor, um conhecido integrante da tradição dos eruditos modernos, ao traçar o painel do romantismo literário europeu deu pouca atenção a figuras capitais como Nietzsche, Marx, Freud, Saussure (que alimentarão também os pós-modernos), preferindo mostrar o lado mais positivo, inspirado e iluminado do pensamento romântico. Como contraponto à abordagem de Abrams, Hillis Miller cita as leituras de Nietzsche feitas por Deleuze, Derrida, Paul de Man, entre outros. Outra crítica de Hillis Miller se refere à interpretação moderna oferecida por Abrams sobre a visão de mundo romântica: após a fragmentação da unidade inicial, os opostos resultantes, parte do conjunto original, anseiam pela reunião. A tal leitura Hillis Miller contrapõe esta outra:

No lugar da noção de que a origem é a unidade, Nietzsche, Deleuze ou Derrida colocariam a ideia de uma diferença ou diferenciação primária [...]. No lugar da noção de opostos [...] Nietzsche colocaria a ideia de graus de diferença, forças diferenciadas que não são opostos, mas pontos na mesma escala, distinções da mesma energia [...] (MILLER, 1972, p.12).

Abrams, professor de Cornell que teve como tutor, em Cambridge, o próprio I. A. Richards (figura máxima do New Criticism), e que advogava, conforme Richter, um "pluralismo histórico 'desestruturado"' (RICHTER, 2008), respondeu às críticas de Hillis Miller através do artigo What's the use of theorizing about the arts (1972). Para armar sua defesa, Abrams recorreu a outro pluralista, Wittgenstein, que dizia que a "perspectiva afeta tanto o que ele está apto a ver quanto o que ele vê como" (BOOTH, 1976, p.412). Em sua resposta, Abrams reage ao desconstrucionismo por meio da defesa do emprego de critérios complexos de julgamento por parte da crítica:

Eu de fato acredito que possuamos critérios válidos para julgar quando a crítica é boa e quando é má [...]. Mas também penso que é um erro presumir [...] que esses critérios são simples e óbvios, ou que são similares aos critérios para distinguir entre uma resposta correta e uma errada a um problema matemático ou a uma questão de fato empírico (apud BOOTH, 1976, p.414).

Assim, sua história da literatura romântica não é completamente questionável, como querem 
os desconstrucionistas, mas apresenta um determinado grau de validade objetiva dentro de uma perspectiva pluralista de história.

Aproveitando então a oportunidade propiciada por este embate entre Hillis Miller e Abrams, Booth publica em 1976 M. H. Abrams: historian as critic, critic as pluralist. Booth e Abrams não pertencem à mesma linha de pluralismo: a escola de Booth defende a construção de modelos e métodos racionais de crítica literária (o pluralismo se percebe na admissão de vários métodos, e não de apenas um), enquanto o pluralismo de Abrams fundamenta-se na análise mais intuitiva das obras, que evidentemente não se pretende a única possível. Booth deixa essas diferenças claras quando chama Abrams, mais de uma vez, de "platônico" (não nos esqueçamos de que o próprio Booth é “aristotélico"). Outra observação de Booth é relativa ao método: Abrams usa validações extrínsecas para apoiar suas interpretações da história do romantismo, o oposto do que fazem os críticos de Chicago, preocupados com provas intrínsecas, isto é, localizadas no interior do próprio texto literário. Booth quer saber se, com tal método intuitivo, Abrams está apresentando uma história do romantismo ou a história do romantismo. Mas Booth não questiona apenas Abrams. Seu objetivo maior é questionar os críticos desconstrucionistas e defender os variados tipos de pluralismo. Assim, em um diálogo imaginário entre Abrams e seus críticos (recurso retórico que Booth frequentemente adota), Booth sugere que Abrams defenda seu pluralismo histórico nos seguintes termos:

É justamente por isso que, nos assuntos humanos, nenhum relato pode ser suficiente. Não é apenas justo que devamos tolerar uma pluralidade de histórias, devemos exigi-las; qualquer um que possa se satisfazer com apenas uma é vítima de uma visão monista da vida humana e de suas causas (BOOTH, 1976, p.438).

Booth imagina ainda outra acusação a Abrams que, vinda de um crítico desconstrucionista, poderia soar plausível:

Mas você caracteristicamente transformou a acusação em uma com a qual é mais fácil de lidar do que a real. $\mathrm{O}$ fato é, como Miller argumenta, que Abrams não é de modo algum um pluralista em sua teoria interpretativa; ele é um dogmático do tipo mais espalhafatoso. Ele parece bastante inconsciente da radical ambigüidade de todos os textos. Ele não dá nenhum sinal de ter lido seu antigo estudante, Harold Bloom [...], ou a obra daquele genuíno pluralista, sr. Roland Barthes (BOOTH, 1976, p.440).

Na mesma edição do Critical Inquiry em que aparece o texto de Booth, a resposta de Abrams, Rationality and imagination in cultural history: a reply to Wayne Booth, é publicada. Abrams, em primeiro lugar, recusa a classificação de "platônico": "[...] não acredito que exista uma entidade abstrata, chamada Romantismo, cujas características essenciais são definíveis; ou para colocar de 
outro modo, que nós podemos estabelecer as condições necessárias e suficientes para o uso correto do termo "romantismo"” (ABRAMS, 1976, p.450). Quanto ao pluralismo histórico, sua primeira posição é esta: "diversos historiadores têm o direito de focar sua atenção em diferentes áreas da preocupação histórica" (ABRAMS, 1976, p.452). Abrams, como Booth, não deixa de mencionar William James em seu texto, mas sua principal preocupação é responder, mais uma vez, aos desconstrucionistas: julga inócuos os princípios de interpretação que defendem; em suas palavras, se fossem levados a sério, "qualquer história que se baseia em textos escritos se torna uma impossibilidade" (ABRAMS, 1976, p.458). Além disso, apresenta um limite bem claro para seu pluralismo: "eu não aceitaria uma história genuinamente escrita de acordo com radicais princípios desconstrucionistas de interpretação" (ABRAMS, 1976, p.458). Abrams, finalmente, procura formular a diferença entre demonstração humanista e demonstração científica recorrendo ao papel do leitor com relação à primeira:

Uma demonstração humanista, diferentemente da demonstração científica, raramente obtém o reconhecimento de todos os observadores qualificados. Isto porque conduzir o leitor através de sua exposição até sua conclusão requer algum espaço para consentimento imaginativo, algum ordenamento comparativo de valores, alguma disponibilidade de resposta emocional aos assuntos demonstrados, que o leitor deve compartilhar com o autor mesmo antes de começada a leitura; e esses espaços comuns são sem dúvida em parte temperamentais, logo, variáveis de leitor para leitor (ABRAMS, 1976, p.464).

Hayden White, em seu Historical Pluralism, de 1986, resume a polêmica entre Abrams e Booth, e também o texto "Critical Inquiry" and the Ideology of Pluralism (1982), publicado por W. J. T. Mitchell, então editor do Critical Inquiry. Mitchell, que se anuncia pluralista dialético, também ataca os desconstrucionistas, que prefere chamar de pan-textualistas, uma vez que acabam por "construir um pan-textualismo que lê todo o tecido da natureza e da cultura como uma rede de signos" (MITCHELL, 1982, p.617). O interesse de White pelos textos polêmicos dos pluralistas reside no fato de que todos eles abraçam um conceito unívoco e não-problemático de história (logo, aparentemente monista e historicista). Mitchell diz que a fragilidade dos pan-textualistas seria uma espécie de consciência deficiente do sentido de história, o que White muito estranha, pois pensava que "um pluralista, e especialmente um pluralista dialético, teria sustentado que 'nosso sentido de história' pudesse ser tão variado quanto as posições críticas que ele quisesse mediar" (WHITE, 1986, p.481). White insiste longamente na pluralidade do conceito de história:

Na realidade, se atentarmos para a teoria e prática histórica contemporânea, temos de admitir que existem tantas perspectivas em história quanto existem modos de prática crítica nos estudos literários. $\mathrm{E}$ isto por uma razão muito boa: o referente do termo "história" é tão indeterminável [...] quanto o termo 
"literatura" (ou ainda "filosofia" ou "ciência"). Assim, se desejamos "corrigir" certas posições críticas lembrando seus proponentes da necessidade de um apropriado "sentido da história", seria igualmente legítimo corrigir o corretor lembrando-o de que a história da historiografia apresenta o mesmo tipo de confusão sobre o "sentido da história" que a história da crítica apresenta sobre o "sentido de literatura" (WHITE, 1986, p. 482).

White tem em mente um conceito bem claro de pluralismo histórico: "Pois o pluralismo histórico pressupõe tanto uma quantidade de relatos igualmente plausíveis do passado histórico ou, alternativamente, uma quantidade de diferentes mas igualmente significativas construções daquele campo indeterminado da ocorrência passada, que por convenção chamamos de 'história'” (WHITE, 1986, p.484). E é justamente esse conceito que não encontra onde seria de se esperar, entre os pluralistas militantes da crítica e da história da literatura. Por que isto acontece?

A hipótese de White é a seguinte: com a fragmentação dos estudos humanísticos em várias disciplinas e com a necessidade de conferir cientificidade a elas, surge a necessidade de se buscar segurança em uma outra disciplina. Para os críticos literários pluralistas, a disciplina segura é a história. White define a si mesmo como "um genuíno pluralista e um que está mesmo preparado para receber o rótulo de relativista radical em questões relacionadas ao conhecimento histórico" (WHITE, 1986, p.486). Logo, não se trata de simplesmente criticar por esta via os pluralistas analisados e adotar o partido dos pan-textualistas. White é pluralista como os pluralistas que critica, mas seu pluralismo é mais abrangente, uma vez que engloba também o conceito de história. Outra questão conexa levantada por White ao final de seu texto é a íntima ligação entre pluralismo histórico e narrativa:

Evidentemente nada falei sobre as alternativas a uma representação narrativa da história. Mas se não o fiz, foi porque para aqueles que negam a adequação da narrativa historiográfica para a representação de eventos reais, a questão do pluralismo não se coloca. Para os historiadores não- ou antinarrativistas contemporâneos, os relatos históricos são ou verdadeiros, ou falsos, inteligíveis ou não inteligíveis. E isto sugere que toda a questão do pluralismo, tanto na crítica quanto na historiografia, está ligada de alguma maneira crucial a uma noção narrativista de representação histórica (WHITE, 1986, p.483).

Dito de outro modo, para os pluralistas (caso de White, sabidamente) a narrativa histórica não apenas é aceitável, como é também desejável, uma vez que já se parte do pressuposto de que existe a possibilidade de vários relatos históricos plausíveis sobre um mesmo ponto, por exemplo. Para os monistas, por outro lado, esse aspecto inerentemente subjetivo e, logo, variável da narrativa é um revés, logo, não são poucos os que pensaram ou os que continuam a pensar em alternativas para substituí-la. 
É chegada a hora de recapitularmos: Hayden White, ele mesmo autodenominado pluralista, critica Abrams, Booth e Mitchell por não possuírem um conceito suficientemente pluralista de história. No entanto, como todos eles, acredita que as humanidades não devem imitar os procedimentos das ciências naturais, mas assumir a arte como método, isto porque ciência e artes possuem lógicas de funcionamento diversas. Provavelmente este é o limite do pluralismo de White: o seu conceito não suficientemente pluralista de ciência. Karl Popper, cujo conceito de historicismo como teoria que defende a existência de um enredo pré-determinado na história - White já deu mostras de apreciar ${ }^{4}$ - tocará justamente nesta limitação de boa parte dos historiadores em seu texto A pluralistic approach to the philosophy of history, publicado em 1969. Logo, um pouco antes de todas as polêmicas que vimos até aqui tomarem corpo. A proposta de Popper pode soar radical até mesmo entre cientistas: ele está de acordo com a seguinte epígrafe escolhida por George Thomson, o prêmio Nobel em Física que descobriu a natureza ondulatória do elétron, para seu livro The inspiration of Science: “A ciência é uma arte” (cf. POPPER, 2003, p.189). Popper defende que "a ciência é muito mais parecida com a história do que pensa o historiador" (POPPER, 2003, p.190). Esta semelhança, no entanto, está bem longe de ser a que os historiadores usualmente imaginam, isso porque o cientismo que por vezes abraçam, entendendo-se por cientismo a paródia dos métodos das ciências naturais, baseia-se no que imaginam serem tais métodos, e não nos métodos reais dessas ciências. A semelhança entre ciência e história reside no uso que ambas fazem da imaginação artística (a elaboração de problemas e de soluções originais está intensamente relacionada a especulações criativas e a insights, lampejos intuitivos) e da análise lógica de informações. Na pesquisa histórica, Popper destaca dois procedimentos importantes: o reenactement, teorizado por Cooligwood e de caráter subjetivo (isto é, a reconstituição dramática dos eventos estudados na mente do historiador) e a lógica situacional (isto é, a tentativa de compreensão da combinação de eventos e ideias contidos em um determinado problema investigado pelo historiador) postulada pelo próprio Popper e de caráter objetivo. Popper afirma que a tarefa mais importante do historiador é a de "oferecer argumentos objetivos que amparem sua análise situacional" (POPPER, 2003, p. 198). Ao afirmar isso, não exclui a necessidade do re-enactement, bem entendido, apenas não lhe concede a posição principal. É na análise situacional que historiador e cientista, para Popper, se encontram: "o método objetivista da análise situacional permite a discussão crítica de nossas soluções provisórias - de nossas tentativas de reconstruir a situação, e, sob esse aspecto, isso é de fato muito próximo do verdadeiro método das ciências naturais" (POPPER, 2003, p.198). Hayden White, ainda que em muitos pontos divirja de Collingwood, como ele se interessa pela dimensão subjetiva do trabalho historiográfico e prefere se ocupar das questões que ela impõe à historiografia. Isto não torna a sua visão incompatível com a de Popper, no entanto. Ambos são pluralistas históricos, e o pluralismo concede que tanto teorias voltadas para tópicos 
subjetivos (o modo como o historiador expressa formalmente seus pontos de vista pessoais no texto histórico, e o modo como isso afeta a própria configuração dos resultados de pesquisa) quanto para tópicos objetivos (o modo como os problemas históricos eleitos são analisados pelo historiador) convivam e sejam igualmente válidas.

\section{Referências Bibliográficas}

ABRAMS, M. H. Rationality and imagination in cultural history: a reply to Wayne Booth. Critical Inquiry, v. 2, n. 3, p. 447-464, Spring 1976.

BAKER, John Ross. From Imitation to Rhetoric: The Chicago Critics, Wayne C. Booth and Tom Jones. NOVEL: A Forum on Fiction, v. 6, n. 3, p. 197-217, Spring 1973.

BOOTH, Wayne. Pluralism in the Classroom. Critical Inquiry, v. 12, n. 3, p. 468-479, Spring 1986.

BOOTH, Wayne C. M. H. Abrams: historian as critic, critic as pluralist. Critical Inquiry, v. 2, n. 3, p. 411-445, Spring 1976.

GOMBRICH, E. H. The state of art history: A plea for pluralism. The American Art Journal, n. 3, p. 83-87, 1971.

JAMES, William. A pluralistic universe. Hibbert Lectures at Manchester College on the Present Situation in Philosophy [1909]. Disponível em: http://www.gutenberg.org/etext/11984. Acesso em: 02 out. 2008.

KRAEMER, Don. Achieving the High Intention?: Wayne Booth's Pluralist Equivalence and Postmodern Difference. College English, v. 52, n. 4, p. 377-384, Apr. 1990.

MILLER, J. Hillis. Tradition and Difference. Diacritics, v. 2, n. 4, p. 6-13, Winter 1972.

MITCHELL, W. J. T. "Critical Inquiry” and the Ideology of Pluralism. Critical Inquiry, v. 8, n. 4, p. 609-618, Summer 1982.

POPPER, Karl. A pluralistic approach to the philosophy of history. In: STREISSLER, Erich (ed.). Roads to Freedom, Essays in honor of Friedrich A. von Hayek. New York: Routledge USA, 2003. p. 181-200.

RICHTER, David. Pluralism at the Millennium. 2008. Disponível em: http://qcpages.qc.cuny.edu/ENGLISH/staff/richter/pluralism.htm.

Acesso em: 01 out. 2008.

RUSSELL, John. Why not pluralism? The Journal of Philosophy, Psychology and Scientific Methods, v. 6, n. 14, p. 372-378, Jul. 1909.

SPRINKER, Michael. What is living and what is dead in Chicago Criticism. boundary 2, v. 12, n. 2/3, p. 189-212, On Humanism and the University II: The Institutions of Humanism (Winter Spring, 1985). 
WHITE, Hayden. Historical Pluralism. Critical Inquiry, v. 12, n. 3, p. 480-493, Spring 1986.

WIMSATT, Jr. W. K. The Chicago Critics. Comparative Literature,v. 5, n. 1, p. 50-74, Winter 1953.

\section{NOTAS}

${ }^{1}$ Todas as citações de textos originalmente em inglês foram traduzidas pela autora.

${ }^{2}$ Mais sobre a Escola de Chicago pode ser visto em BAKER (1973) e WIMSATT (1953), este último um influente New Critic que combate duramente os pressupostos do Chicago Criticism e, em especial, o pensamento de McKeon.

${ }^{3}$ Como se lê no seguinte trecho: "Estou dizendo que o pluralismo como projeto intelectual pode desafiar nossa experiência primária de modo muito semelhante à forma como William James afirma que conceitos e definições sempre fazem. James escreve sobre o 'uso privativo' dos conceitos, a prática de presumir de que excluem o que não afirmam” (BOOTH, 1986, p.476).

${ }^{4}$ White cita várias vezes A pobreza do historicismo, de Popper, sempre de modo positivo, em Historicismo, História e a Imaginação Figurativa, ensaio publicado em Trópicos do Discurso.

Artigo recebido em 10/2009. Aprovado em 12/2009. 